\title{
Molecular Structural Analysis of Spider's Capture Thread and Viscid Droplets Studied by Microscopic FT-IR Spectroscopy
}

\author{
Hironobu Yabe, ${ }^{*}$ Norihisa Katayama, ${ }^{* \dagger}$ and Mitsuhiro MiYazawa** \\ *Graduate School of Natural Sciences, Nagoya City University, 1 Yamanohata, Mizuho, Nagoya 467-8501, \\ Japan \\ **Institute of Agrobiological Sciences, NARO, 1-2 Ohwashi, Tsukuba, Ibaraki 305-8634, Japan
}

\begin{abstract}
The molecular structural analysis of capture thread, including its viscid droplets of oriental golden orb-web spider Nephila clavata, has been performed by microscopic FT-IR spectroscopy. The obtained spectra of capture threads with and without viscid droplets indicate that the features in the region of $1400-1000 \mathrm{~cm}^{-1}$ will be useful as marker bands for the degree of the dissolving of viscid droplet; further, the bands at 1395 and $1335 \mathrm{~cm}^{-1}$ are attributable to the components of anchoring granules located at the inner side of viscid droplets. By recrystallization and its infrared measurements, the main chemical component of viscid droplets is assignable to glycosylated proline. It has also been demonstrated that the components of the anchoring granule of a viscid droplet are decomposed by UV irradiation, and that the molecular conformation of silk fiber protein of a capture thread is denatured at over $60^{\circ} \mathrm{C}$, whereas the viscid droplets on a capture thread retain their structure.
\end{abstract}

Keywords Spider silk, capture thread, viscid droplet, microscopic FT-IR, UV exposure, heat denaturation

(Received September 3, 2016; Accepted November 28, 2016; Published January 10, 2017)

\section{Introduction}

Spider's threads, which are fibrous silk proteins, have characteristic properties both regarding strength and elasticity. Examinations for industrialization by mimic spider silk of the drag line have been an actively challenged cause of the outstanding properties on strength. ${ }^{1,2}$ Most studies concerning analyses of the secondary molecular structure of proteins in the drag line have proposed that the silk consists of highly oriented crystalline $\beta$-sheets embedded in a matrix of disordered amorphous structures. ${ }^{3-6}$ On the other hand, the capture threads of an orb-web have important roles, such as being a trap for flying insects for their feed. Thus, so the capture threads indicate the peculiar physical properties regarding elasticity and viscidity. However it has been well known for a long time that the capture thread contains viscid droplets on the silk fiber protein, study on the molecular structure and functional mechanism of the capture threads has been very few compared with that for the drag line. ${ }^{7}$ The capture threads of orb-web spiders consist of two extensible axial fibers surrounded by aqueous adhesive glue. ${ }^{8-11}$ At first, the glue covers the fibers evenly, but it is soon spontaneously forms into a series of regularly distributed droplets. ${ }^{12-14}$ It has also been reported that the property of a viscid droplet shows strange behavior, such as an in-drop capillary spooling of the thread. ${ }^{15}$ These marvelous properties of a spider's capture thread seem to encourage and inspire the developments of high-performance new materials involving hybrid fibers. ${ }^{15,16}$

† To whom correspondence should be addressed.

E-mail: nory@nsc.nagoya-cu.ac.jp
In this study, microscopic FT-IR spectroscopy was applied to reveal the relationship between the molecular structure and the properties in the natural capture threads of the spider silk of the oriental golden orb-web spider, Nephila clavata. This study indicates that the chemical component of the viscid droplets of the capture thread has been identified to be the glycosylated proline molecule, which is easily dissolved and recrystallized by the spraying of distilled water. It has also been studied that the molecular conformation changes of the silk fiber protein and the viscid droplets of the spider's capture thread by heat and UV irradiation.

\section{Experimental}

\section{Sample preparation}

The oriental golden orb-web spider, Nephila clavata, is reared in clean cases individually so as to avoid them from attacking each other. The capture thread of the adult spider's orb-web was naturally collected on a $\mathrm{CaF}_{2}$ substrate by means of handmade instruments. For removing the viscid droplets from the fiber thread, distilled water was carefully sprayed. A handy type UV lamp $\left(254 \mathrm{~nm}, c a .1 \mathrm{~mW} \mathrm{~cm}^{-1}\right)$ was used for the exposure of UV light. A Mettler-Toledo HS82 microscope hotstage was employed for temperature control.

\section{Measuring of infrared spectra}

Measurements of IR spectra were performed by using a Spectrum One FT-IR spectrometer (Perkin Elmer) equipped with a microscope apparatus. The spectra were accumulated in the region of $4000-800 \mathrm{~cm}^{-1}$ with a $4-\mathrm{cm}^{-1}$ resolution and an aperture unit of $100 \mu \mathrm{m}$ in diameter. 


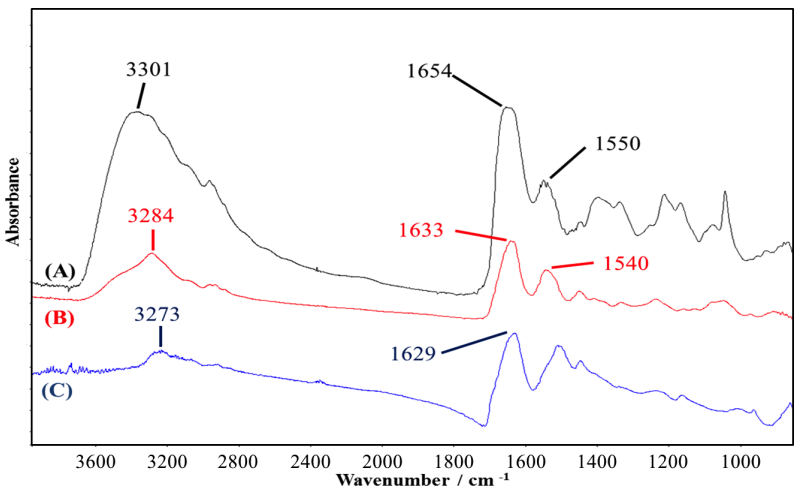

Fig. 1 IR spectra of spider silks. (A) Capture thread covered with discid droplet; (B) capture thread without viscid droplet; (C) dragline.

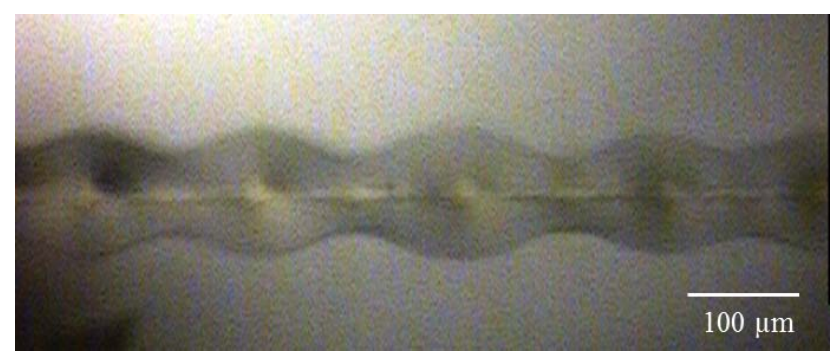

Fig. 2 Photomicrograph of a capture thread.

\section{Results and Discussion}

Figure 1 shows the IR spectra of the capture threads of Nephila clavata covered by viscid droplets (A) and without any viscid droplet (B); the IR spectrum of the spider's dragline is compered in Fig. 1(C). The features near 1650 and $1550 \mathrm{~cm}^{-1}$ are assignable to the amide I and amide II bands of protein, respectively, ${ }^{6,17-19}$ while a broad band at $3300 \mathrm{~cm}^{-1}$ is attributed to water contained in the viscid droplets of the spider's thread. In comparison with spectra (A) and (B), the characteristic features near to the $3300 \mathrm{~cm}^{-1}$ and bands in the region of $1400-1000 \mathrm{~cm}^{-1}$ in the spectrum (A) are assignable due to viscid droplets being on the capture threads. The broad band at $1654 \mathrm{~cm}^{-1}$ is attributable to overlapped bands due to the protein molecule of the viscid droplets and fiber proteins of the capture threads. In a comparison of spectra (A) and (B), it is indicated that the protein molecule of the viscid droplets is considerably rich concerning $\alpha$-helix and random structures, while that of the fiber-formed protein involves $\beta$-sheets rich structure.

A photomicrograph of the capture thread on a $\mathrm{CaF}_{2}$ plate is illustrated in Fig. 2. This picture shows that the silk fiber of the capture thread is covered with a composite material comprising micron-sized viscoelastic droplets. In a previous study, viscid droplets consisted of aqueous solutions of sugar protein and low-molecular-weight hygroscopic salts; also, the chemical components were different between the center and outer parts of the viscid droplets. ${ }^{8-11}$ Upon spraying distilled water, the viscid droplets gradually dissolved, and the chemical component was recrystallized on $\mathrm{a} \mathrm{CaF}_{2}$ substrate by dry up. A photomicrograph of the recrystallized material is shown in Fig. 3. The obtained polarized IR spectra of this crystal exhibit an anisotropic feature near to $1350 \mathrm{~cm}^{-1}$, suggesting that the main chemical component of the recrystallized viscid droplets can be assignable to

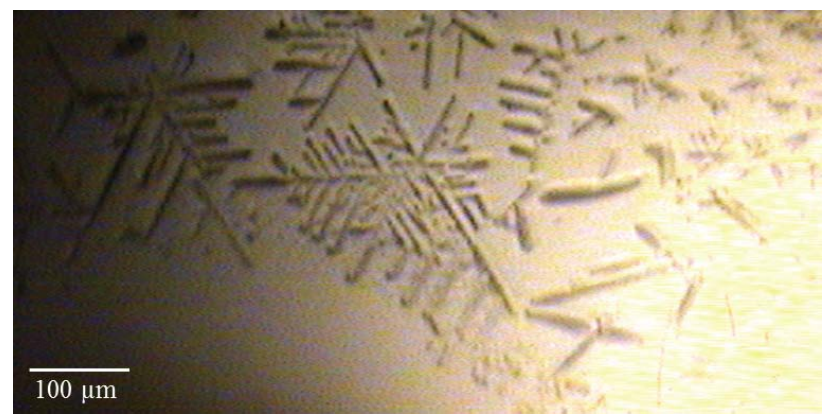

Fig. 3 Photomicrograph of recrystallized viscid droplets.

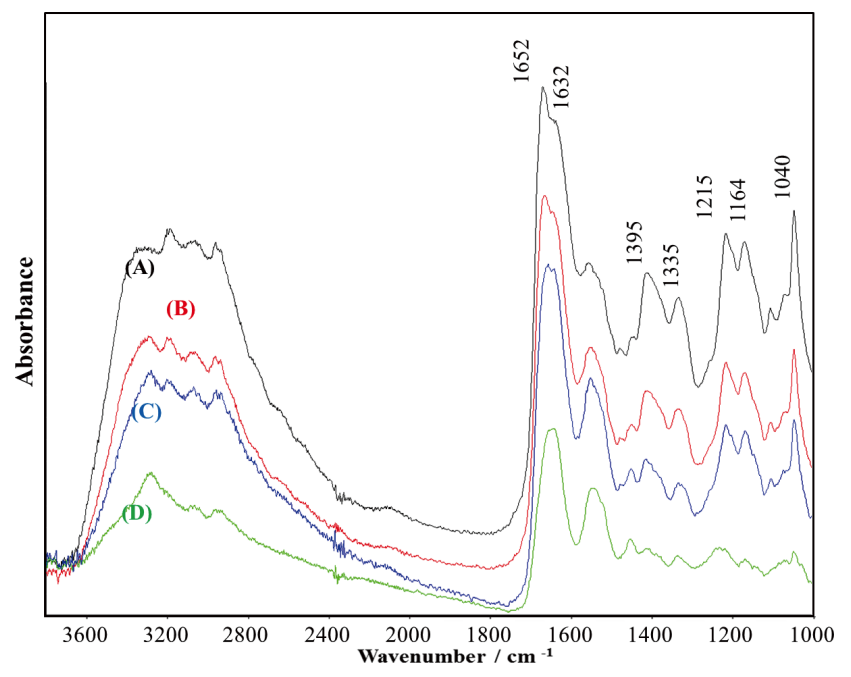

Fig. 4 IR spectral changes with respect to the water dissolving of the viscid droplet of a capture thread. (A) Before spraying; (B) on the dissolved outer side of the viscid droplet; (C) on the dissolved inner side of the viscid droplet; (D) after dissolving the viscid droplet.

glycosylated proline. This result is consistent with recent reports..$^{20,21}$

Figure 4 compares the IR spectral changes of the capture thread with regard to water dissolving of viscid droplets. While the characteristic bands in the region of $1400-1000 \mathrm{~cm}^{-1}$ arising from the viscid droplets strongly appear in the spectrum before spraying water (Fig. 4(A)), this feature is weaker at the beginning of dissolving the outer side of the viscid droplet (Fig. 4(B)). On the other hand, the bands at 1395 and $1335 \mathrm{~cm}^{-1}$ are rather weak in the spectrum due to dissolving of the inner side of the viscid droplet (Fig. 4(C)). The feature in the region of $1400-1000 \mathrm{~cm}^{-1}$ is considerably weak in the obtained spectrum for after dissolving of the viscid droplet (Fig. 4(D)). These results suggest that the feature in region of 1400 $1000 \mathrm{~cm}^{-1}$ is useful as marker bands for the degree of dissolving of the viscid droplet. It also represents that the bands at 1395 and $1335 \mathrm{~cm}^{-1}$ can be attributable to the components of the anchoring granule, which is located on the inner side of the viscid droplet. Figure 5 shows the IR spectra of the capture thread under UV exposure. With increasing the UV exposure time, the bands at 1395 and $1335 \mathrm{~cm}^{-1}$ due to the components of the anchoring granule of the viscid droplet are considerably decreased, whereas the bands at 1215 and $1164 \mathrm{~cm}^{-1}$ due to the viscid droplet are not particularly decreased. This result 


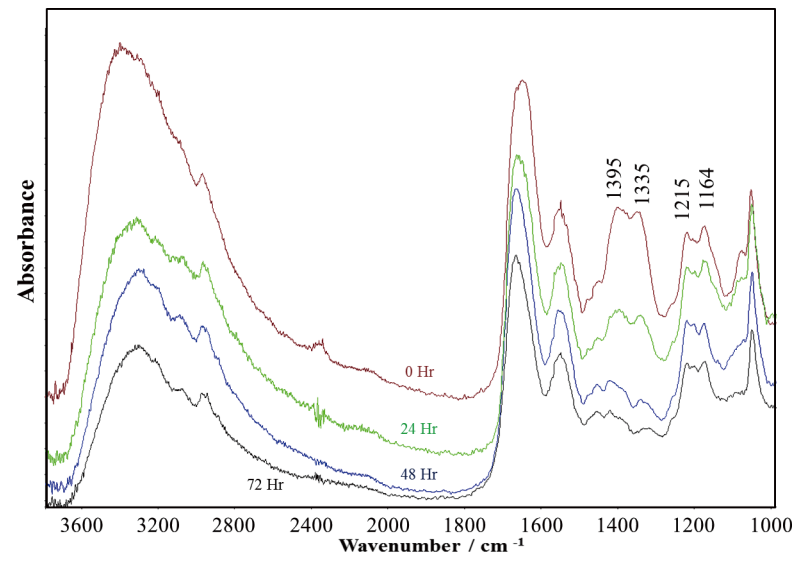

Fig. 5 IR spectral changes of the capture thread with respect to UV exposure.

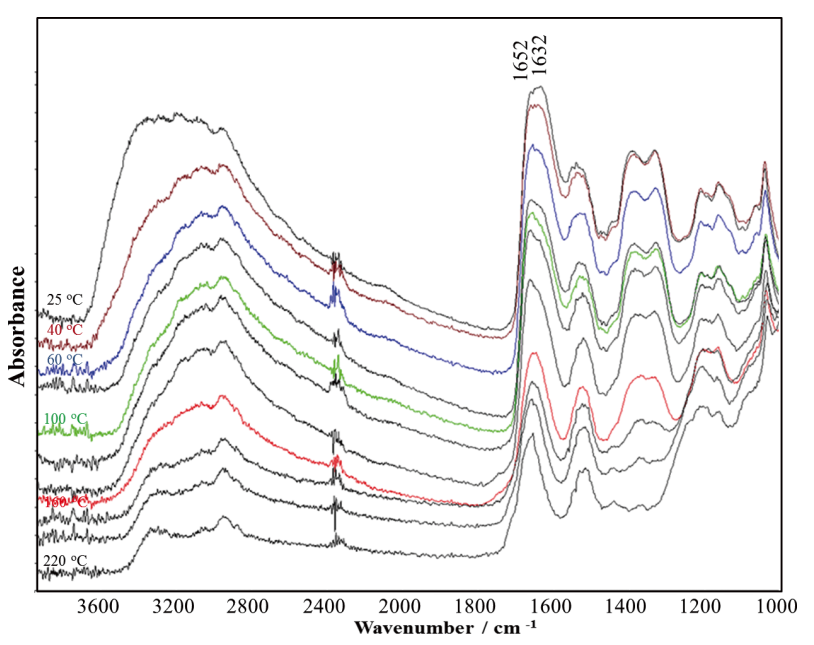

Fig. 6 IR spectral changes of the capture thread with respect to increasing temperature. The temperature was increased from $25^{\circ} \mathrm{C}$, and every $20^{\circ} \mathrm{C}$ from 40 to $220^{\circ} \mathrm{C}$.

indicates that the components of the inner side of the viscid droplet are decomposed by UV irradiation.

The spectral changes during increasing temperature of the capture thread are represented in Fig. 6. The measurement temperatures were at $25^{\circ} \mathrm{C}$ and every $20^{\circ} \mathrm{C}$ from 40 to $220^{\circ} \mathrm{C}$. Upon increasing of temperature by over $60^{\circ} \mathrm{C}$ the band intensity at $1632 \mathrm{~cm}^{-1}$ assigned to the $\beta$-sheet structure of the amide I band decreased in relation to the intensity at $1652 \mathrm{~cm}^{-1}$, assigned to the $\alpha$-helix structure of amide I band. However, the feature in the region of $1400-1000 \mathrm{~cm}^{-1}$ due to the viscid droplets began to decrease over $160^{\circ} \mathrm{C}$. These results suggest that the molecular conformation of the silk fiber protein of the spider's capture thread is denatured at over $60^{\circ} \mathrm{C}$, whereas the viscid droplets on the capture thread retain their structure.

\section{Conclusions}

In this study, an analysis of the molecular structure of a spider's capture thread by means of microscopic FT-IR was conducted. It was demonstrated that the glycosylated proline molecule, which is the main component of viscid droplets on capture thread, is recrystallized by the spraying of distilled water, and that the components of the inner side of the viscid droplet are decomposed by UV irradiation. It was also revealed that the molecular conformation of the silk fiber protein of the spider's capture thread is denatured by at lower temperature, whereas the viscid droplets on the capture thread retain their structure. These results seem to arise from the important roles of viscid droplets for the physical and chemical properties of silk fiber proteins of the capture thread.

\section{References}

1. M. Denny, J. Exp. Biol., 1976, 65, 483.

2. F. G. Omenetto and D. L. Kaplan, Science, 2010, 329, 528.

3. A. H. Simmons, C. A. Michal, and L. W. Jelinski, Science, 1996, $21,84$.

4. C. Y. Hayashi, N. H. Shipley, and R. V. Lewis, Int. J. Biol. Macromol., 1999, 24(2), 271

5. M. Heim, L. Romer, and T. Scheibel, Chem. Soc. Rev., 2010, 39, 156.

6. F. Paquet-Mercier, T. Lefèvre, M. Aguer, and M. Pézolet, Soft Matter, 2013, 9, 208.

7. J. M. Gosline, C. C. Pollak, P. A. Guerette, A. Cheng, M. E. DeMont, and M. W. Denny, in "Silk Polymers, Materials Science and Biotechnology", ed. D. Kaplan, W. W. Adams, B. Farmer, and C. Viney, 1994, Vol. 544, Chap. 27, ACS Symp., Washington, D.C., 328.

8. H. M. Peters, in "Ecophysiology of Spiders", ed. W. Nentwig, 1986, Springer Verlag, New York, 187.

9. F. Vollrath, W. J. Fairbrother, R. J. P. Williams, E. K. Tillinghast, D. T. Bernstein, K. S. Gallagher, and M. A. Townley, Nature, 1990, 345, 526.

10. E. K. Tillinghast, M. A. Townley, T. N. Wight, G. Uhlenbruck, and E. Janssen, Mat. Res. Soc. Symp. Proc., 1991, 292, 2.

11. B. D. Opell, S. E. Karinshak, and M. A. Sigler, J. Exp. Biol., 2011, 214, 2988.

12. R. F. Foelix, "Biology of Spiders", 2nd ed., 1996, Chap. 5, Oxford University Press, New York, 122.

13. B. D. Opell and H. S. Schwend, J. Exp. Zool., 2008, 309A, 11.

14. V. Sahni, T. A. Blackledge, and A. Dhinojwala, J. Adhes., 2011, 87, 595.

15. H. Elettroa, S. Neukircha, F. Vollrathb, and A. Antkowiaka, Proc. Natl. Acad. Sci. U. S. A., 2016, 113, 6143.

16. T. A. Blackledge and C. Y. Hayashi, J. Exp. Biol., 2006, 209, 2452.

17. W. H. Moore and S. Krimm, Biopolymers, 1976, 15, 2465.

18. E. Goormaghtigh, V. Cabiaux, and J. M. Ruysschaert, "Physicochemical Mothods in the study of Bioomembranes", ed. H. J. Hilderson and G. R. Ralston, 1994, Vol. 23, Plenum Press, New York, 404.

19. M. Boulet-Audet, T. Buffeteau, S. Boudreault, N. Daugey, and M. Pézolet, J. Phys. Chem. B, 2010, 114, 4537.

20. M. A. Collin, T. H. Clarke, N. A. Ayoub, and C. Y. Hayashi, Sci. Rep., 2016, 6, 21589.

21. H. Shinohara and E. K. Tillinghast, Biochem. Int., 1984, 9, 315 . 